\title{
Editorial: Participatory research and evaluation approaches in developing contexts: reviewing evidence on professional practice and capacity development
}

\author{
Akanksha A. Marphatia ${ }^{1} \cdot$ Karen Edge $^{2}$ \\ Published online: 1 April 2015 \\ (C) Springer Science+Business Media New York 2015
}

We embarked on the development of this special issue with a clear intention to curate a collection of articles for Educational Assessment Evaluation and Accountability (EAEA) and to capture the current theory, practice and debates associated with participatory evaluation and research in developing contexts. This special issue coincides with a growing international and national interest in participatory methods for research, evaluation and policy implementation. However, like many others, we remain concerned that across many contexts 'participation' constitutes little more than a oneoff consultation along with an exclusion from decision-making processes. We firmly believe, rooted in the evidence presented in this issue and beyond, that participatory processes must be continuous from the onset and consider the personal and collective experience of participants.

The discussions and debates that have inspired this special issue arose from our longstanding professional collaboration on participatory approaches. Our partnership has centred on applying these methodologies in collaboration with community practitioners, policy decision-makers and academic researchers. With this in mind, we introduce the overarching themes emerging from the three papers and two commentaries.

In the first article, 'The journey from rhetoric to reality: Participatory evaluation in a development context', Choinard and Cousins provide a systematic review of 40 studies published over the past 16 years. The authors define participatory evaluation as the process of the co-production of evaluative knowledge derived from a partnership

Akanksha A. Marphatia

aam54@cam.ac.uk

$\triangle$ Karen Edge

k.edge@ioe.ac.uk

1 Department of Geography, University of Cambridge, Downing Place, Cambridge CB2 3EN, UK

2 London Centre for Leadership in Learning, UCL Institute of Education, University of London, 20

Bedford Way, London WC1H 0AL, UK 
between programme community members and evaluation professionals. Their analysis uncovers eight themes that highlight the current tensions and debates including, but not limited to, the lack of conceptual and methodological clarity of what constitutes a participatory evaluation. By articulating the need for evidence-based principles to guide collaborative inquiry and participatory practice, the authors highlight the first theme of this issue: the contradiction between the need for theoretical precision of participatory approaches and, simultaneously, the origination of such efforts from local cultural and institutional contexts.

Following this overview of current participatory practices and evidence, in 'Recalibrating baseline evidence in Burundi, Malawi, Senegal and Uganda: Exploring the potential of multi-site, national-level stakeholder engagement in participatory evaluation', Edge and Marphatia present an unique framework for nurturing social networks and building individual capacity to create new knowledge that guided the collaborative collection of evidence from over 6000 stakeholders. This initiative aimed to foster greater collaboration among a wide range of stakeholders to generate a more robust evidence base on how the quality of teaching and parental participation can better contribute to improved student learning outcomes. This paper articulates the second theme of the issue: that participatory processes are often established to solve a problem or explore an issue; uncovered in this process are the assumptions of whose 'knowledge' and experience is valued. The underlying principal of participation, in our view, is to ensure that all voices are not only listened to, but also heard through a systematic and rigorous evaluation or research process, from project conception through to reporting on findings.

Next, Kendall, Kuanda and Friedson-Rideneur explore 'Community participation in international development education quality improvement efforts: Current paradoxes and opportunities'. The authors examine the origins and implementation of the Participatory Action for School Improvement (PASI) project in Malawi. They remind us of the historical colonial relations, often enacted through international institutions that impinge on 'respectful partnership'. The article presents an instructive and candid explanation of the various (and often contentious) steps required to support genuine engagement in implementing or evaluating community-driven initiatives. This contribution highlights the third theme woven throughout the issue: the politics and power hierarchies embedded in each step of participatory processes.

The final contributions to this special issue comprise commentaries and reflections on the influence of participatory process on the gendered realities practiced in everyday life and the teaching profession. First, Sudarshan argues that an increased level of social engagement, in the form of action research, is not only required, but perhaps the most promising potential for challenging the deep-rooted ideologies regarding women's roles in the dominant patriarchal practices of India. Although gender parity in (primary) education has been an important goal, progress in achieving this milestone has not facilitated greater gender equality or a marked shift in societal norms. This is partly because so many education systems still reproduce social inequality in support of the dominant hierarchies, failing to create even the possibility of a new social identity for women and men.

Finally, Muskin brings the series to a close by assessing why such pathways of change are not yet created in classrooms. The reflective practice model does much more than discuss how to help teachers become educators. It challenges the very de- 
professionalization of teachers who are endowed with the responsibility of teaching our children yet provided insufficient pedagogical support, trust or authority to adapt their own practice to the heterogeneity of today's culturally diverse classrooms. Under such circumstances, a new societal identity, or expanded community and parental participation in education, as advocated in the other articles in this series, is simply not possible.

While there remains little agreement of a common definition of participatory processes of research and evaluation, an increasing body of practice and research evidence centres on the fundamental concepts of the purpose and assumptions motivating such efforts. This issue has highlighted some of the common themes and areas of concern, including who participates, for what outcome, on what type of initiatives, under what conditions, at what point in the process, and in which ways.

Within the research and policy spheres, the evidence remains sparse in relation to the extent to which any critical awareness about social inequalities gained from participatory approaches successfully changes the very attitudes and behaviours maintaining power imbalances. For example, Sudarshan's commentary questions whether actionbased research creates a 'cognitive dissonance' which enables people to challenge the unjust structures and mechanisms reproducing their marginalisation. Nevertheless, both Sudarshan and Kendall and colleagues articulate that the potential of participatory approaches to support conscientisation, as envisioned by Friere, is enormous. The evidence of the emancipatory potential of participatory methodologies is still unknown, however, partly because evaluations are not systematically conducted after such participatory processes conclude. Muskin's experience is an exception since the professional capacity of the teacher as an individual person, is considered as much as their ability as professional. Future assessment of this approach in different contexts currently underway would provide instructive evidence of how both professional and personal practice may change as a result of participatory methodologies

How such initiatives facilitate changes in wider policy and social practices also requires further investigation. While the participatory effort of Kendall and colleagues was successful in supporting increased community ownership and leadership in improving local schools, the authors candidly question the success of such efforts in directly changing the policy or projects in Malawi more broadly. The participatory process conceived and jointly implemented by multi-stakeholder teams in Edge and Marphatia's experience also highlights the need for a longer-term framework to manage and rebalance the underlying power relations underpinning the perceptions and ownership of knowledge and expertise.

While the articles contained in this special issue make strides towards developing and challenging current conceptions of the pragmatics of design, implementation and influence of participatory practices, there are many debates that remain uncovered. We strongly encourage others to continue the debates and dialogues in academic, policy and practice circles. Participatory processes will remain part of the ongoing practice and theory of work in developing and developed contexts. It is our collective role to ensure that debates around the co-production of knowledge, challenging dominant hierarchies, gender and the long-term influence of participation remain at the forefront of these discussions. 